\title{
Use of dirty plastic waste as precursors for activated carbon production-A contribution to the circular economy
}

The production of activated carbons (ACs) from dirty plastic wastes derived from the mechanical/biological treatment of urban solid wastes, disposable plastics and plastics used in agriculture is reported. The use of these precursors is innovative and contributes to the circular economy by the valorization of dirty plastics that are usually disposed in landfills. ACs were produced by physical activation, with air or $\mathrm{CO}_{2}$, and chemical activation, with $\mathrm{KOH}$ or $\mathrm{K}_{2} \mathrm{CO}_{3}$. ACs presented a $\mathrm{BET}\left(\mathrm{N}_{2}\right)$ area and pore volume up to $723 \mathrm{~m}^{2} / \mathrm{g}$ and $0.32 \mathrm{~cm}^{3} / \mathrm{g}$. Selected samples were tested for the 2,4dichlorophenoxyacetic acid (MCPA) and 4-chloro-2-methyl-phenoxyacetic acid (2,4-D) removal from the liquid phase. $\mathrm{PB}-\mathrm{K}_{2} \mathrm{CO}_{3}-1: 1-700$ presented an apparent maximum adsorption capacity of 245 and $289 \mathrm{mg} \mathrm{g}^{-1}$ for MCPA and 2,4-D, respectively. 